\title{
Differential Expression of DUB Genes in Ovarian Cells Treated with Di-2-Ethylhexyl Phthalate
}

\author{
Da-Hye Lee ${ }^{1}$, Jun-Hyeok Park ${ }^{1}$, Jihye Choi ${ }^{1}$, Kyung-Ju Lee ${ }^{2}$, Bo-Seong Yun ${ }^{3}$ and \\ Kwang-Hyun Baek 1,*D \\ 1 Department of Biomedical Science, CHA University, Gyeonggi-Do 13488, Korea; \\ po1290@hanmail.net (D.-H.L.); nymwns1@naver.com (J.-H.P.); gihea392@naver.com (J.C.) \\ 2 Department of Obstetrics and Gynecology, Korea University Anam Hospital, \\ Korea University College of Medicine, Seoul 02841, Korea; drlkj4094@gmail.com \\ 3 Department of Obstetrics and Gynecology, Gangnam CHA Hospital, College of Medicine, CHA University, \\ Seoul 06135, Korea; bosungyun@chamc.co.kr \\ * Correspondence: baek@cha.ac.kr; Tel.: +82-31-881-7134
}

Received: 10 January 2020; Accepted: 3 March 2020; Published: 4 March 2020

\begin{abstract}
Premature ovarian failure (POF) is defined as loss of ovarian function in women less than 40 years of age. The causes of POF are diverse and include environmental factors. Di-2-ethylhexyl phthalate (DEHP) is one factor that may cause POF. The ubiquitin-proteasome system maintains intracellular balance by promoting or inhibiting protein degradation. To investigate the differential expressions of deubiquitinating enzyme (DUB) genes in patients with POF, we developed two in vitro POF models by treating A2780 or OVCAR5 with DEHP. Using these models, a multiplex RT-PCR system for $D U B$ genes was applied to identify biomarkers by comparing expression patterns and DUB mRNA levels; multiplex RT-PCR results were validated by qRT-PCR and Western blotting analyses. Observed differential expression levels of several DUB genes including USP12, COPS5, ATXN3L, USP49, and USP34 in A2780 and OVCAR5 cells at the mRNA and protein levels suggest that they should be investigated as potential biomarkers of POF.
\end{abstract}

Keywords: DEHP; deubiquitinating enzyme; toxic environmental factor; multiplex RT-PCR; premature ovarian failure; qRT-PCR

\section{Introduction}

Ubiquitination is an essential process that results in the degradation of dispensable proteins via the ubiquitin-proteasomal pathway (UPP) [1]. Protein ubiquitination is mediated by a series of enzymatic actions by ubiquitin-activating enzymes (E1), ubiquitin-conjugating enzymes (E2), and ubiquitin ligases (E3) [1,2]. As its name implies, deubiquitination is the inverse of ubiquitination, and deubiquitinating enzymes (DUBs) play a crucial role in protein stabilization by removing ubiquitin ( $\mathrm{Ub}$ ) from conjugated target proteins by hydrolyzing the isopeptide bonds of Ub-substrates. These ubiquitin-associated systems maintain intracellular protein balance by promoting or inhibiting degradation. The human genome codes for $~ 100$ DUBs, most of which are classified as members of seven subfamilies; that is, ubiquitin C-terminal hydrolases (UCHs), ubiquitin-specific proteases (USPs), JAB1/MPN/Mov34 metalloenzymes (JAMMs), otubain proteases (OTUs), Machado-Joseph disease proteases (MJDs), permutated papain fold peptidases of dsDNA viruses and eukaryote monocyte (PPPDEs), and motif interacting with Ub-containing novel DUB family (MINDY) [3-5]. The biological functions of DUBs are not completely understood yet.

Premature ovarian failure (POF) involves loss of ovarian function in women less than 40 years old, which means ovaries do not produce normal amounts of estrogen and ovulation occurs sporadically and 
results in infertility [6]. POF can be present as primary amenorrhea with no menarche or as secondary amenorrhea with no menstrual period for 6 months or no menstrual period more than three times after the previous menstrual period [6]. The cause of POF is unclear, but it is known that both genetic and environmental factors are involved. Known causes include chromosomal abnormalities, autoimmune diseases, metabolic disorders, enzyme deficiencies, ovarian damage, and genetic diseases $[7,8]$.

Environmental diseases are health disorders caused by physical, chemical, or biological environmental factors, often because of exposure to toxic environmental factors associated with lifestyle and occupational activities. Furthermore, it has been established that POF can be caused by toxic environmental factors [9].

Phthalates are one of the toxic environmental factors that may cause POF [10]. Phthalate esters are alkyl diesters of phthalic acid and are widely used as plasticizers, and are known to adversely affect two essential ovarian processes; that is, folliculogenesis and steroidogenesis [10]. Di-2-ethylhexyl phthalate (DEHP) is a member of the class of phthalates, and the relationship between DEHP and POF has been investigated, showing that the mechanistic link between the two has been elucidated [11-13]. One of the previous studies demonstrated that DEHP disrupts estrous cyclicity and PI3K signaling [14].

In order to investigate the differential expression of $D U B$ genes and identify potential biomarkers of POF, we designed a multiplex PCR primer library of DUB genes [15] and treated two in vitro POF models, that is, A2780 and OVCAR5 ovarian cell lines, with DEHP, and confirmed results by qRT-PCR and Western blotting analyses [16]. Our results showed the differential expressions of mRNA and protein for several DUB genes including Ataxin-3-like protein (ATXN3L), Ubiquitin specific peptidase 12 (USP12), Ubiquitin specific peptidase 49 (USP49), COP9 signalosome subunit 5 (COPS5), and Ubiquitin specific peptidase 34 (USP34) in A2780 and OVCAR5 cells.

\section{Results}

\subsection{Differential Expressions of DUBs by DEHP in Ovarian Cells}

To investigate DUB genes associated with DEHP, ovarian cell lines were treated with different concentrations of DEHP (Table 1) [16]. Multiplex RT-PCR was used to amplify DNA bands of DUB genes from cDNA synthesized from mRNA of A2780 and OVCAR5 cells treated with DEHP. When the multiplex RT-PCR was performed using all 12 sets of primers in the multiplex RT-PCR library, DNA amplification of DUB genes was detected (Figures 1 and 2). Independent experiments were conducted at least three times. The results showed that the mRNA levels of USP12, COPS5, ATXN3L, and USP49 were increased in A2780 cells (Figure 1 and Figure S1), and that the mRNA level of USP49 was increased and that of USP34 was decreased in OVCAR5 cells (Figure 2 and Figure S2) by DEHP exposure in a dose-dependent manner.

Table 1. Concentration of di-2-ethylhexyl phthalate (DEHP) treatment.

\begin{tabular}{ll}
\hline Ovarian Cells & DEHP (di-2-ethylhexyl phthalate) \\
\hline A & $0 \mu \mathrm{g} / \mathrm{mL}(0 \mathrm{mM})$ \\
B & $1 \mu \mathrm{g} / \mathrm{mL}(2.77 \mathrm{mM})$ \\
C & $10 \mu \mathrm{g} / \mathrm{mL}(27.7 \mathrm{mM})$ \\
D & $100 \mu \mathrm{g} / \mathrm{mL}(277 \mathrm{mM})$ \\
\hline
\end{tabular}

\subsection{DEHP Exposure Influenced the mRNA Levels of Several DUB Genes in Ovarian Cells}

To confirm the result of multiplex RT-PCR, RT-PCR and qRT-PCR were performed for selected DUB genes. The mRNA levels of USP12, ATXN3L, COPS5, and USP49 were increased in A2780 cells by DEHP (Figure 3a and Figure S3a), and in OVCAR5 cells, the mRNA level of USP34 was decreased and that of USP49 was increased (Figure 3b and Figure S3b). Furthermore, these results were confirmed by qRT-PCR (Figure 3c and Table S1). 
a
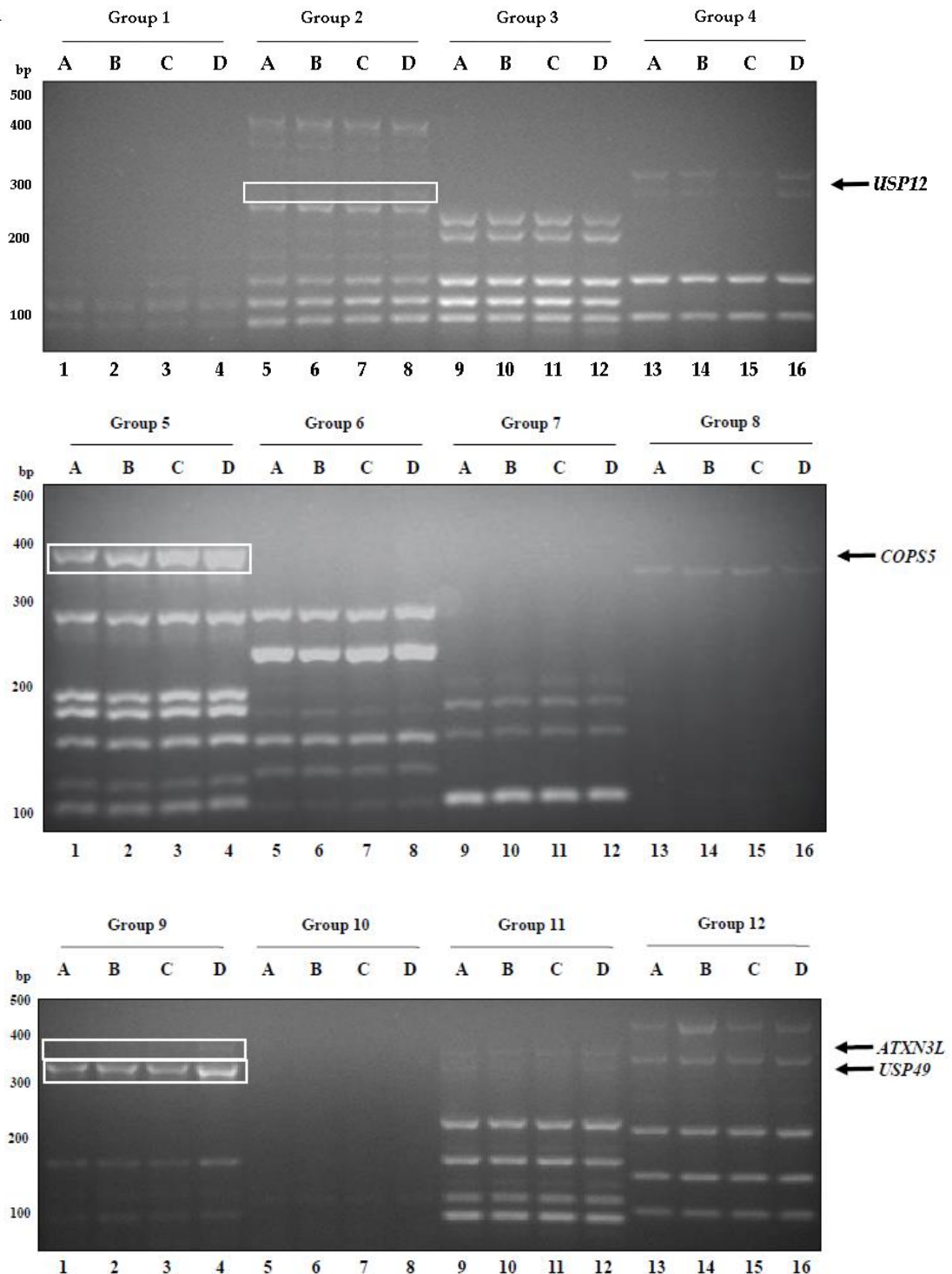

b

A2780 cells

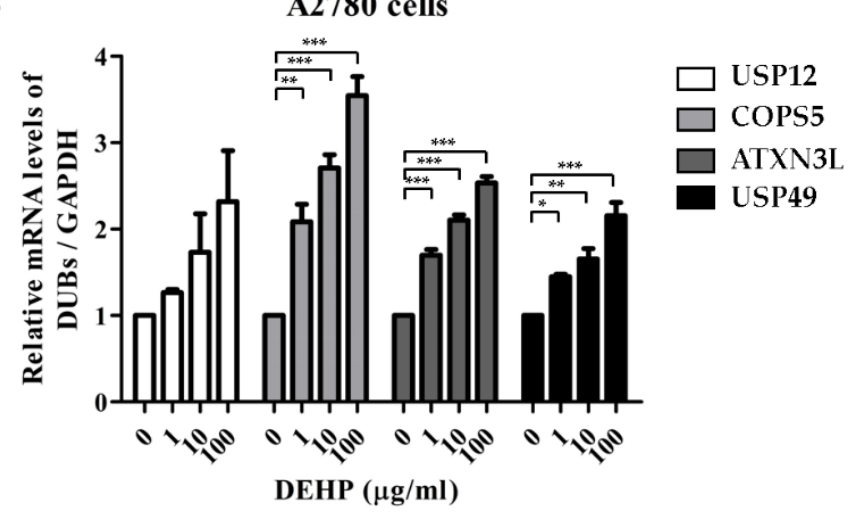

Figure 1. Deubiquitinating enzyme (DUB) gene screening in A2780 cells treated with DEHP using the multiplex RT-PCR primer library. (a) DUB genes were amplified by multiplex RT-PCR using 12 sets of primer library. (b) mRNA levels of USP12, COPS5, ATXN3L, and USP49 were normalized with respect to $G A P D H$. The significances of differences were determined by one-way of variance. $p$-values are presented as ${ }^{*} p<0.05,{ }^{* *} p<0.01$, or ${ }^{* *} p<0.001$. 

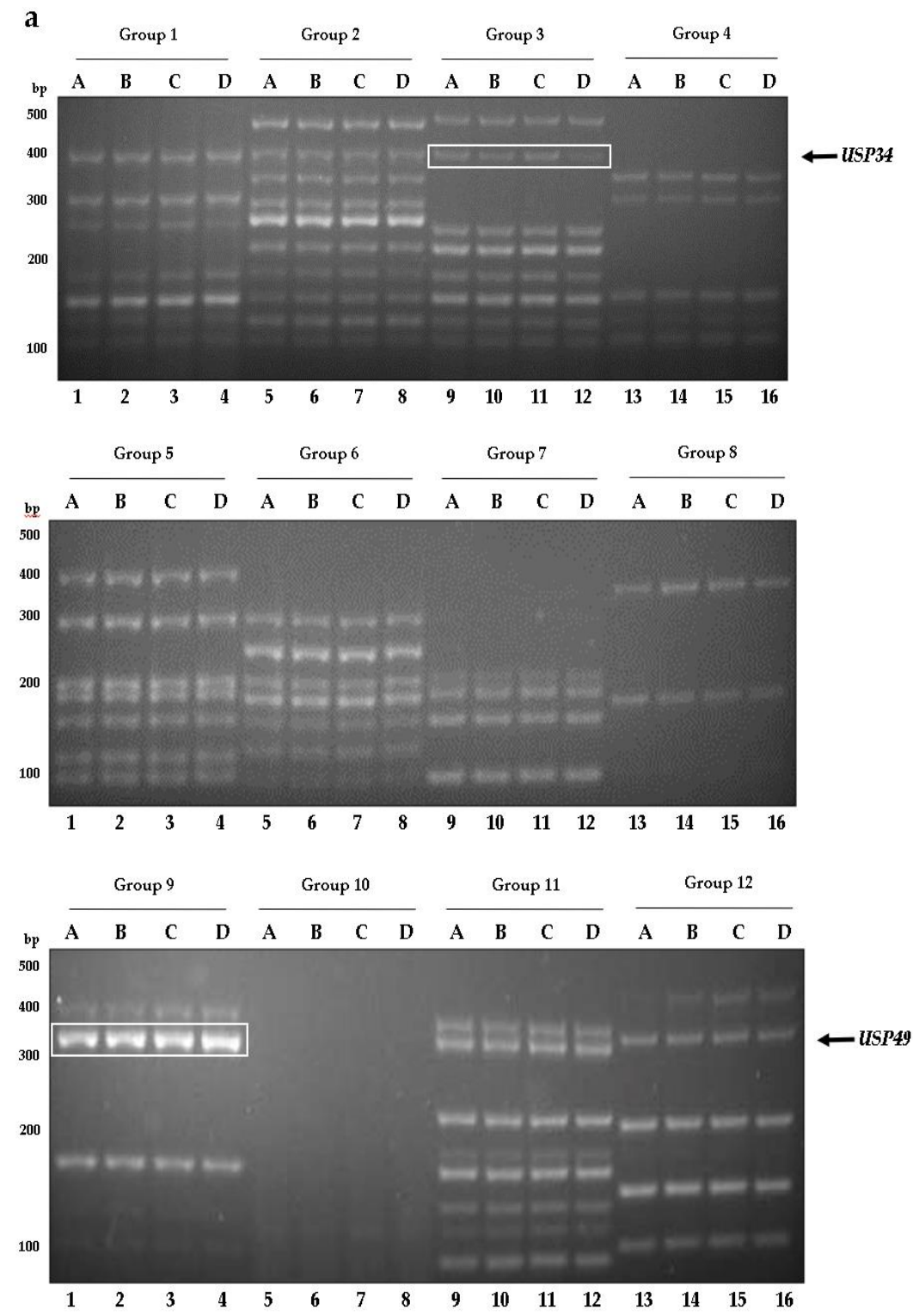

b

\section{OVCAR5 cells}

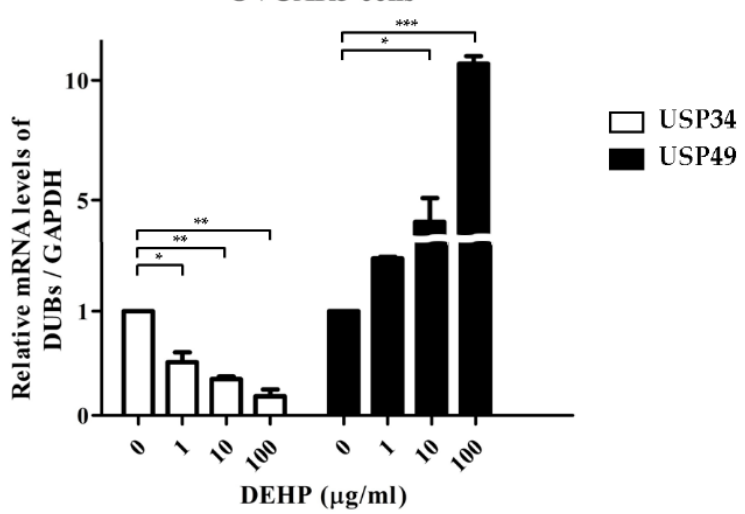

Figure 2. DUB gene screening in OVCAR5 cells treated with DEHP using the multiplex RT-PCR primer library. (a) DUB genes were amplified by multiplex RT-PCR using 12 sets of primer library. (b) mRNA levels of USP34 and USP49 were normalized with respect to GAPDH. The significances of differences were determined by one-way of variance. $p$-value are presented as ${ }^{*} p<0.05,{ }^{* *} p<0.01$, or ${ }^{* * *} p<0.001$. 
A2780 cells

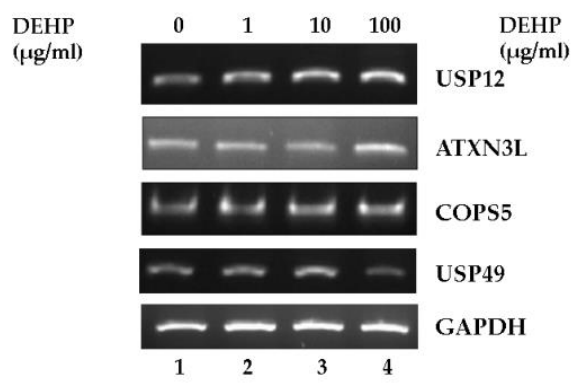

OVCAR5 cells

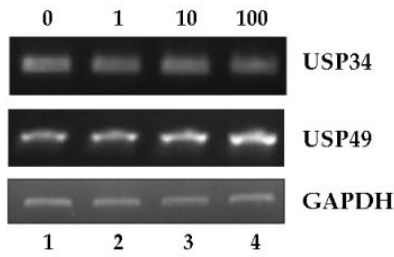

b

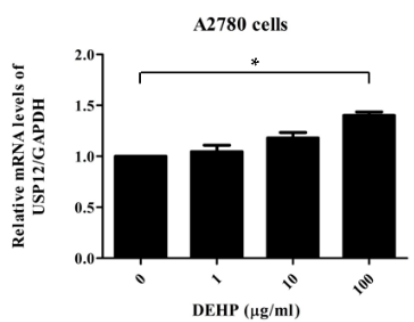

A2780 cells

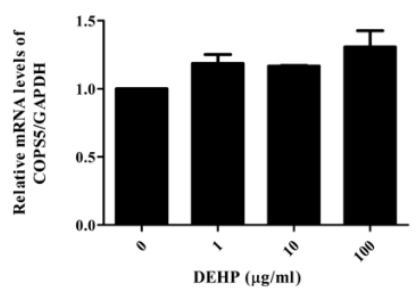

c
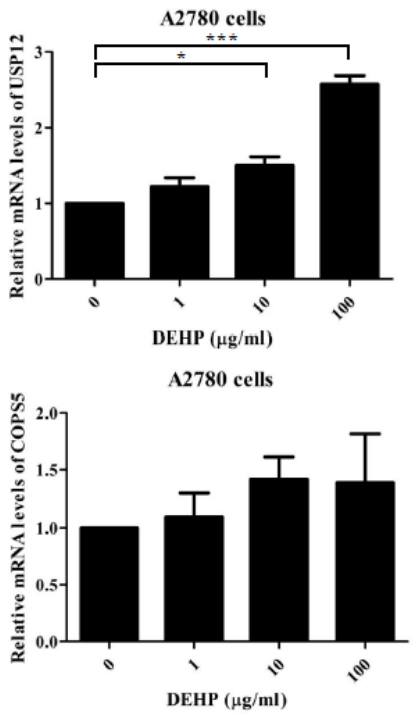

A2780 cells

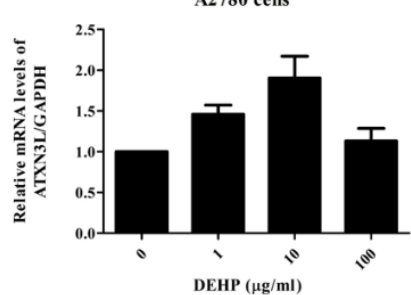

A2780 cells

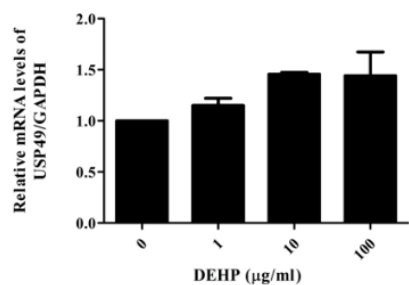

A2780 cells

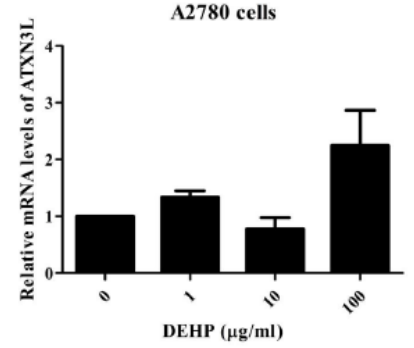

A2780 cells

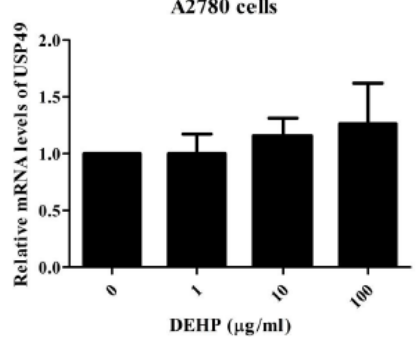

OVCAR5 cells

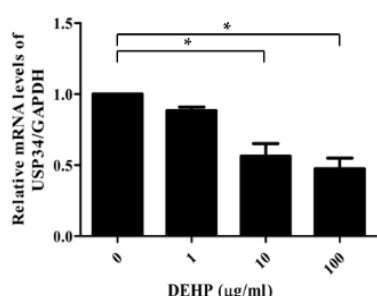

OVCAR5 cells

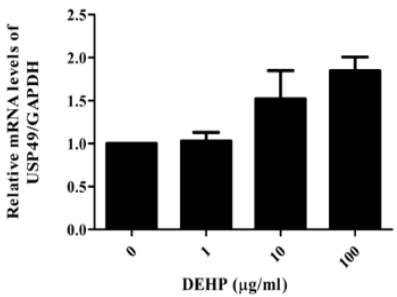

OVCAR5 cells

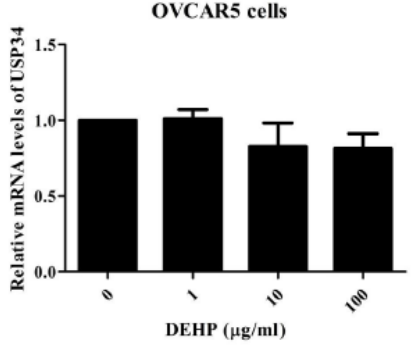

OVCAR5 cells

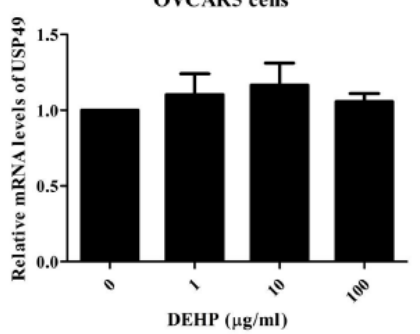

Figure 3. The mRNA expressions of DUB genes in DEHP-treated cells. (a) mRNA levels were assessed by RT-PCR in A2780 and OVCAR5 cells treated with different concentrations of DEHP. (b) The mRNA levels of $D U B$ genes were normalized with respect to GAPDH. (c) The mRNA levels of DUB genes were examined by qRT-PCR in A2780 and OVCAR5 cells treated with different concentrations of DEHP. The significances of differences were determined by one-way of variance. $p$-values are presented as * $p<0.05$, or ${ }^{* * *} p<0.001$. 


\subsection{Up-Regulation of USP49 Protein by DEHP in Ovarian Cells}

As the mRNA level of USP49 was found to be upregulated by DEHP in ovarian cells (Figure 3), we examined the effects of DEHP exposure on the protein level of USP49 in both cell lines by Western blotting analysis. As was expected, the protein levels of USP49 were upregulated in both cell lines by DEHP (Figure 4 and Figure S4).
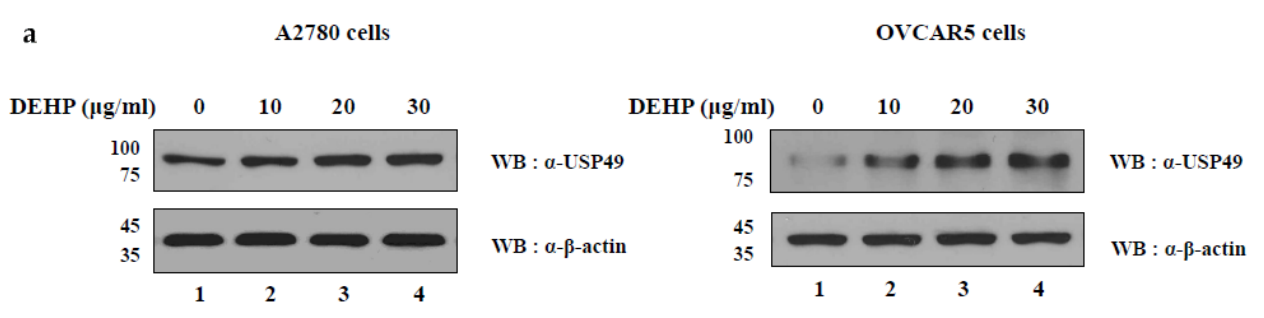

b
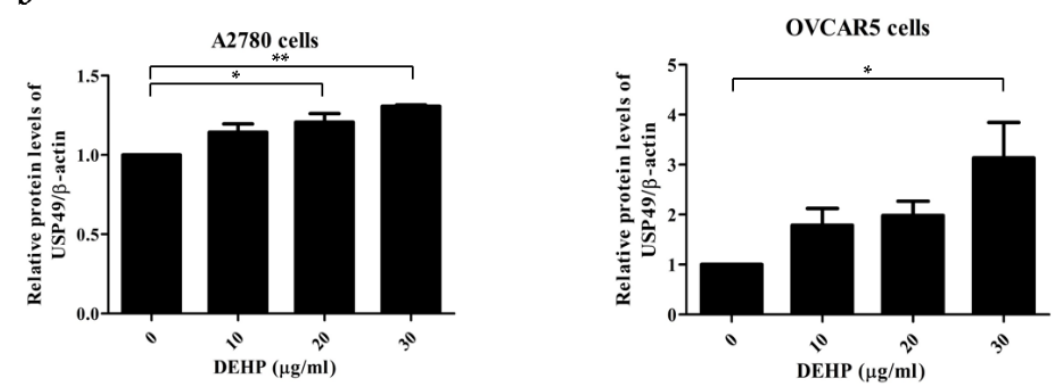

Figure 4. Expression of USP49 in the DEHP-treated cells. (a) Protein levels of USP49 in A2780 (left) and OVCAR5 (right) cells treated with DEHP were determined by Western blotting. (b) USP49 band intensities were normalized versus $\beta$-actin. The significances of differences were determined by one-way of variance. $p$-values are presented as ${ }^{*} p<0.05,{ }^{* *} p<0.01$.

\section{Discussion}

Exposure to toxic environmental factors is steadily increasing because they continue to be used in daily life, and as a result, the incidences of the diseases they cause are also increasing. On the other hand, progress is being made to develop products using less toxic materials. POF is a disease associated with toxic environmental factors in addition to genetic factors, and its incidence is also increasing. Therefore, we investigated mechanisms involving the ubiquitin-proteasome system initiated by exposure to DEHP in ovarian cell lines by using multiplex RT-PCR to screen for DUB genes differentially expressed after DEHP exposure.

ATXN3L is a Machado-Joseph disease protease (MJD), which contains the Josephin domain (JD), and JD containing proteins are known to have deubiquitination activity [17]. Furthermore, it has been shown that ATXN3L has greater deubiquitination activity than JD containing proteins [18]. Furthermore, ATXN3L is a DUB of Krüppel-like factor 5 (KLF5) and promotes breast cell proliferation, survival, and tumorigenesis [19]. In the present study, multiplex RT-PCR results showed that ATXN3L expression was increased in A2780 cells after DEHP exposure, suggesting that this would promote POF by promoting oocyte maturation, due to its cell proliferation capability [18].

USP12 is a ubiquitin-specific protease (USP) and a component of a complex containing USP1-associated factor 1 (UAF1) and WDR20. It also regulates androgen receptor (AR) in prostate cancer [20-22]. USP12 has been shown to regulate the ubiquitination level of histone H2A and H2B [23] and to deubiquitinate AR and MDM2, which regulate the p53-MDM2-AR-AKT signaling network. In addition, USP12 promotes cell survival, proliferation, tumorigenesis, and cell cycle progression by upregulating BMI-1, c-Myc, and cyclin D2 [24-27]. Our multiplex RT-PCR results showed that USP12 expression was increased by DEHP in A2780 cells, and thus, the above-mentioned findings of 
its influence on cell cycle progression and proliferation suggest that it may induce POF by influencing oocyte maturation.

On the other hand, USP49 is also a ubiquitin-specific protease and regulates the initial pre-mRNA splicing by deubiquitinating histone H2B [28]. USP49 is also known to regulate tumorigenesis by regulating the involvement of p53 in DNA damage response and by controlling FK506-binding protein 51 (FKBP51) through the Akt signaling pathway [29,30]. Multiplex RT-PCR and Western blot analysis revealed that USP49 was upregulated by DEHP in A2780 and OVCAR5 cells. These findings suggest that USP49 upregulation by DEHP induces cell death via p53 regulation, which subsequently leads to POF due to follicle depletion.

COPS5 is a JAB1/MPN/Mov34 metalloenzyme. Its expression increases during oocyte maturation and it is required for oocyte meiosis. COPS5 also regulates the maturation-promoting factor (MPF) activity [31]. Furthermore, progesterone receptor (PGR), which regulates ovulation, lies downstream of COPS5 [32,33]. COPS5 has been reported to control proliferation and inhibits the expression of p27 in serous ovarian cancer [34]. Our multiplex RT-PCR results showed that COPS5 expression was increased in A2780 cells exposed to DEHP. Based on the above, COPS5 upregulation would be expected to promote POF by promoting oocyte maturation.

USP34 is a ubiquitin-specific protease that controls the stability of Axin and positively regulates $\mathrm{Wnt} / \beta$-catenin signaling [35]. USP34 is required for DNA damage repair and regulates E3 ubiquitin-protein ligase RNF168, and recruits the DNA damage repair factors by ubiquitinating DNA double-strand breaks (DSBs) [36]. It has also been shown to negatively regulate $\mathrm{T}$ cell receptor (TCR) by inhibiting nuclear factor- $\mathrm{KB}(\mathrm{NK}-\mathrm{\kappa B})$ activation [37], and to be associated with polycystic ovary syndrome (PCOS), one of the most common endocrine disorders among women [38]. In the present study, multiplex RT-PCR results showed that USP34 was downregulated by DEHP in OVCAR5 cells, which suggests a diminished ability to repair DNA damage and increase the risk of POF due to reductions in follicle numbers.

In summary, this study shows that DEHP changes the mRNA and protein levels of several DUB genes; that are, USP12, ATXN3L, COPS5, USP49, and USP34 in the A2780 and OVCAR5 cells, and that it could potentially participate in the pathogenesis of POF. We suggest an in vivo study to be undertaken in a rodent model to further investigate the link between the DEHP-induced differential expressions of $D U B$ genes and the pathogenesis of POF and to identify potential therapeutic targets.

\section{Materials and Methods}

\subsection{Cell Culture}

Human ovarian cancer cell lines, A2780 cells, were grown in the Roswell Park Memorial Institute-1640 medium (11875-093, RPMI-1640, Gibco BRL, Rockville, MD, USA) and OVCAR5 cells were grown in Dulbecco's modified Eagle's medium (11965084, DMEM, Gibco BRL, Rockville, MD, USA), containing 10\% fetal bovine serum (26140079, FBS, Gibco, Grand Island, NY, USA), and 1\% antibiotic-antimycotic reagent (15240062, Gibco, Tewksbury, MA, USA) at $37^{\circ} \mathrm{C}$ in $5 \% \mathrm{CO} 2$ atmosphere.

\subsection{RNA Extraction and $c D N A$ Synthesis}

For RNA extraction, cells at 80-90\% confluence in $60 \mathrm{~mm}$ dishes were lysed with TRIzol reagent (15596018, Ambion, Carlsbad, CA, USA). cDNA was prepared by reverse transcription with $1 \mu \mathrm{g}$ of total RNA using the LaboPass cDNA Synthesis Kit (CMRTK001, Cosmogenetech Inc, Seoul, Korea) according to the manufacturer's protocols.

\subsection{Multiplex RT-PCR and $q R T-P C R$}

For multiplex RT-PCR, we used 2× Multiplex PCR Smart Mix (SMP01-M25h, Solgent, Daejeon, Korea), $200 \mathrm{ng}$ cDNA samples, and GAPDH as a control. PCR products were separated by $2 \%$ agarose gel electrophoresis and gels were stained with RedSafe DNA Stain (21141, Chembio, Medford, NY, 
USA) to visualize amplicons and confirmed the amplification of cDNA bands of expected sizes. Primers for the multiplex RT-PCR library (Table 2) were used to amplify the DUB-specific sequences (Ubiprotein Corp, Seongnam, Korea). mRNA expression levels were normalized versus GAPDH and analyzed using Image J v1.4.3.67 (National Institutes of Health, Bethesda, MD, USA). Expression levels of DUB genes in naïve A2780 and OVCAR5 cells were considered normal. Primers for qRT-PCR (Table 3) were used to compare the quantitative expression of DUB genes identified through multiplex RT-PCR (Ubiprotein Corp, Seongnam, Korea). qRT-PCR was performed using the StepOne Real-Time PCR System (Thermo Fisher Scientific, Inc., Waltham, MA, USA) according to the manufacturer's instructions, and cDNA was amplified by reverse transcription using SYBR-Green PCR Master Mix (4309155, Applied Biosystems; Thermo Fisher Scientific, Inc., Waltham, MA, USA). Cycle threshold values of $D U B$ genes were normalized to the endogenous reference gene GAPDH. The expression $D U B$ genes levels were calculated using the $2^{-\Delta \Delta C T}$ method.

Table 2. Multiplex PCR primer set.

\begin{tabular}{|c|c|c|c|c|c|}
\hline $\begin{array}{l}\text { DUB } \\
\text { Gene }\end{array}$ & Primer Sequence & Group & $\begin{array}{l}\text { DUB } \\
\text { Gene }\end{array}$ & Primer Sequence & Group \\
\hline \multirow{2}{*}{ Ataxin 3} & F: GTC CAA CAG ATG CAT CGA CCA A & \multirow{2}{*}{ G4 } & \multirow{2}{*}{ USP12 } & F: GAA CTC TGA GTC TGG TTA CAT CCT & \multirow{2}{*}{ G2 } \\
\hline & R: CGT CTA ACA TTC CTG AGC CAT C & & & R: GAG GAG CTG GTA TCT CTG ATT TCA & \\
\hline \multirow{2}{*}{ ATXN3L } & F: TCA GAA GAA AGT GAT GAG TCT GG & \multirow{2}{*}{ G9 } & \multirow{2}{*}{ USP13 } & F: ACC CAG CTG GAC AAT GGA GTC A & \multirow{2}{*}{ G2 } \\
\hline & R: CTC TCA ATT GCT CTC GAA CTT G & & & R: CAG CTT GAT GTC ATT GTC CTG GA & \\
\hline \multirow{2}{*}{ BAP1 } & F: TCC GTG ATC TGG GTC CTG TC & \multirow{2}{*}{ G11 } & \multirow{2}{*}{ USP14 } & F: TCA GTG TAT TCG TTC TGT GCC TGA & \multirow{2}{*}{ G2 } \\
\hline & R: TCC CCG TCT TCT CTC TGC TG & & & R: CTC GCA TCA TTT GTA TCC AAC ATT CA & \\
\hline \multirow{2}{*}{$B R C C 3$} & F: GAG TTC AGA GTA TGA GAG AAT CG & \multirow{2}{*}{ G4 } & \multirow{2}{*}{ USP15 } & F: AAA CCT CGC TCC GGA AAG GGG A & \multirow{2}{*}{ G2 } \\
\hline & R: CCT TTT CTT CTT GTT GTA ATT CCT G & & & R: CAG TTG GCA ACA GTA TGT AAT CCA A & \\
\hline \multirow{2}{*}{ COPS5 } & F: GCA GTG GTG ATT GAT CCA ACA A & \multirow{2}{*}{ G5 } & \multirow{2}{*}{ USP16 } & F: AAA CTT TAG AAC CTG TGT GCA G & \multirow{2}{*}{ G3 } \\
\hline & R: AGA CCT GAC CAG TGG TAT AGT C & & & R: CCT GAG AAT TTC TGC CAC AGC C & \\
\hline \multirow{2}{*}{ COPS6 } & F: AGG TGT TCA AGG AGC TGG AGT T & \multirow{2}{*}{ G5 } & \multirow{2}{*}{ USP17 } & F: GAG CAA CGC AAG GAG AGC TCA AG & \multirow{2}{*}{ G8 } \\
\hline & R: GGA AGA TCT GTG TGC TTG GTC A & & & R: AGG GTA CCT TCG ACT TTT CTG ACG & \\
\hline \multirow{2}{*}{ CYLD } & F: GCC AAG AAA AAG TCA CTT CAC CC & \multirow{2}{*}{ G11 } & \multirow{2}{*}{ USP18 } & F: ATT GGA CAG ACC TGC CTT A & \multirow{2}{*}{ G3 } \\
\hline & R: TGC CTT TTT GCA GAA GGA ATC CT & & & R: AAG GAT TCC TTC ACC CGG ATC G & \\
\hline EIF3S3 & F: GTC CAA АCT CTT CAA ACC ACC A & G5 & USP19 & F: GTT CTT TCC TTC ATC GTC AGG GTC & G3 \\
\hline Lit & R: AGT GAA CTC CTT GAT GTT CTG G & & & R: AGT GGG AGT AGC CAA GAG ATC ATG & \\
\hline EIF3S5 & F: TCT GCC TGG TCC TGC TCT TCC A & G4 & $U$ & F: TGG GCT CCT CTT CCA AGT TCT & G11 \\
\hline & R: TTG TCG ACA GTT CCC AAC AGG G & & & R: AGG TTT CAG GTC ATC GTC CTC T & \\
\hline JOSD1 & F: GTG AAT GTC ATT ATG GCA GCA C & G4 & USP21 & F: TGA CAA AGC CGG AAG TCC TGT A & G3 \\
\hline & R: TCC TCC AAC TCT GAT GAG CCT C & & & R: AAA GGG CTT CAC AGG TGC CAG A & \\
\hline JOSD2 & F: GTG TCT ACT ACA ACC TGG ACT C & G4 & USP22 & F: ACC AAC CAA ACG GGA GCT TG & G11 \\
\hline & R: ATG AAG TGC TGG CCT TTC CCA G & & & R: CCC AAG GTT GAT CAG CCC AC & \\
\hline MPND & F: CGG GCA GAC CTT CAA CTC AC & G12 & USP & F: CCG ACA GTT GTC CGT GTC TG & G12 \\
\hline & R: CCC AGT GGT CTC CGA CTC TT & & & R: TCC GAA GCT GTA GGC ACG TA & \\
\hline ОТИВ1 & F: AGG AAC CTC AGC AGC AGA AGC A & G6 & USP26 & F: CAG CCA CCT GTG AGA CCT GGT AA & G8 \\
\hline & R: GTC TTG CGG ATG TAC GAG TAC T & & & R: CTG ATA ACT CTC CGC AAG TAA G & \\
\hline ОТИВ2 & F: CAT TCT TCG GGA CCA TCC TGA A & G6 & USP27 & F: CTC CAG CTT TAC GAT CGG TTT AAG & G1 \\
\hline & R: GTT CCC ATC CCC TTT GGT CTT & & & R: CCG AAA CAG CGA CGA CAT CTC AC & \\
\hline OTUD1 & F: ATG GGG CAG ATG CTG AAT GTG A & G6 & USP28 & F: GAG GCA GCC CCA ACT GAA TC & G11 \\
\hline & R: TGC ACC AGT TGT CGT ACT CTG & & & R: TGC TCA GAT GAC AAG CAG CG & \\
\hline OTUD3 & F: GAA GAC GAC CTG AGA GAT GAA G & G7 & USP29 & F: GGG ATG ACT AAG CTG AAA GAA GCT & G10 \\
\hline & R: CTG GGC TCA AGA TTC TCT TCT G & & & R: TTT CAA AGT TAA ACG CAG GTG ACT & \\
\hline OTUD4 & F: GCT CTG CTA TGT GTC AGT CTC T & G7 & USP31 & F: TGA GGA TTG GTG TGG CCG TA & G11 \\
\hline & R: TTA CTT GCA ACT GTC ATC CTC TG & & & R: AAT CTT GTC GCT GCC TGC TC & \\
\hline OTUD5 & F: ATC GGA GGA GTC ATG GAT TGA A & G6 & USP33 & F: CCC TTG GTA CTT GTCA GGA TTG TA & G3 \\
\hline & R: ACC TGG CGA GCC TGT TTC TCC T & & & R: AAG CAT AAC ACC ATA CTC GAA GAG & \\
\hline
\end{tabular}


Table 2. Cont.

\begin{tabular}{|c|c|c|c|c|c|}
\hline $\begin{array}{l}\text { DUB } \\
\text { Gene }\end{array}$ & Primer Sequence & Group & $\begin{array}{l}\text { DUB } \\
\text { Gene } \\
\end{array}$ & Primer Sequence & Group \\
\hline \multirow{2}{*}{ OTUD6A } & F: TGG ATG ATC CGA AGA GTG AAC & \multirow{2}{*}{ G10 } & \multirow{2}{*}{ USP34 } & F: CAG CCA TAG TGC TGA AGT TCA AGT & \multirow{2}{*}{ G3 } \\
\hline & R: TCT TGG AAC TTC TCC AGC TCC T & & & R: GAC TGA CAT CAC CAG ATT GTG CT & \\
\hline \multirow{2}{*}{ OTUD6B } & F: AAG AAT GCT GTT CCC AAG AAT G & \multirow{2}{*}{ G7 } & \multirow{2}{*}{ USP35 } & F: AAG TAC ATG CTC CTG ACC TTC CA & \multirow{2}{*}{ G8 } \\
\hline & R: CCA TAT GTC TGG CTC CTG TTA A & & & R: CCC AGG TTG ATG AGA CCA ATC TT & \\
\hline \multirow{2}{*}{ OTUD7A } & F: GCA GCA CTT CTA CAT GAT CCT A & \multirow{2}{*}{ G8 } & \multirow{2}{*}{ USP36 } & F: TCC CAG ACA CCC ACA CAC AT & \multirow{2}{*}{ G12 } \\
\hline & R: TGT GTA GAT TGG CAT CTC CAG G & & & R: GTG GTG TTG TCC GTG TCT G & \\
\hline \multirow{2}{*}{ OTUD7B } & F: ACT TCA CAG GGG TGC CTT GTT & \multirow{2}{*}{ G7 } & \multirow{2}{*}{ USP37 } & F: CAG AAG GAA ACC AGC AGG CA & \multirow{2}{*}{ G12 } \\
\hline & R: GTT CTT CCC TGT AAC AAC AGG A & & & R: CGT CCG AGC TAT TCC ACT TCC & \\
\hline \multirow{2}{*}{ PARP11 } & F: CAG CTA CAA GAT AGA CTT TGC AG & \multirow{2}{*}{ G7 } & \multirow{2}{*}{ USP38 } & F: CGT GTT GGG CCT CCT TCA TC & \multirow{2}{*}{ G11 } \\
\hline & R: GAT GGC CTC GTT TTC ACA GAT G & & & R: TGC AGG GAA GGC AGT AGT GT & \\
\hline \multirow{2}{*}{ PRPF8 } & F: TCT ATG ACG ACT GGC TCA AGA C & \multirow{2}{*}{ G5 } & \multirow{2}{*}{ USP39 } & F: GGA GTC TCG CGG TTC CAC T & \\
\hline & R: ATC GCC ATG CTT GTT GAC AGT G & & & R: CGC ACA AAC GGG ACA ACA GA & \\
\hline GD14 & F: GGT TTG ACA CTT CAG GAC TAC A & G5 & & F: GGT TCT GCT TCA ATG ACT CCA ATA & \\
\hline & R: GAG GTC ATA AGT ACA TCC ACAT G & & & R: AGC CAT CTC ACG ATT GAC CGG CT & \\
\hline PSMD7 & F: ACG TCT TCA ACC TGC TGC CAG A & G5 & & F: TTA CTC ATC CCA CCC ATA GCC & \\
\hline TIVID? & R: TCC TGC CCT TCT TTC TTC TCT G & & & R: TCA TGT GAG AGG GAA GCT GTG GT & \\
\hline$M B P$ & F: GAA GCC CTC CTT AGA TGT GTT & G4 & & F: GAC AGA GCT GTT TCC TGG GC & \\
\hline JTHVIDT & R: TGT CCA CCA CAG GTG GCT TAG CT & & & R: ATA GCT GCA GGC CAC AGA GA & \\
\hline ST & F: TTC GAA GAT CAA CTC AAG AAG CA & G5 & & F: TGG GCT GTT CAG ATC CAG TAG T & \\
\hline & R: TCT GGT GTG TGG AAA AGC AGG A & & & R: ACT GTC AGT CTC CTT GGT GTA CAG & \\
\hline TNFAIP3 & F: CCG AGC TGT TCC ACT TGT TAA CA & G6 & & F: CCA ATC CTG CTG ATG TGG CAG TC & \\
\hline HEVIATH & R: CAA CTT TGC GGC ATT GAT GAG A & & & R: GCT GAT GGC TGG AAA GAT GTA GTA & \\
\hline USP1 & F: GAC CAA ATG TGT GAA ATA GGT AAG C & GL & a & F: CAA TGA TCA ACA TGT CAG CAG GA & G1 \\
\hline Uort & R: GCA AGT AAG GAG TAG AAG TAG GAG & & & R: TTT CTG GCT GGA TCC TTC AGT CT & \\
\hline USP2 & F: TAT GGT GCC TAC ACC CCG TCC T & G9 & USP48 & F: GCT GGT AGA TCG GGA TAA TTC CA & G2 \\
\hline & R: TGA GGA AGC TGC TGG TGG GGA C & & & R: AAC TCA TAG GGC TCA GCT CCA G & \\
\hline USP3 & F: CCT TGG GTC TGT TTG ACT TGT TCA & G3 & USP49 & F: AGG ACT ACG TGC TCA ATG ATA ACC & G9 \\
\hline & R: CCA GTC CCA GCT TGG TGT CAT TA & & & R: GCA GGA GCA GCC GTG CAC TCT & \\
\hline USP4 & F: GTA GAA GGC CAG CAA CCC ATC G & G1 & USP50 & F: CTA TGA TAC CCT TCC AGT TAA GG & G \\
\hline & R: ACT AGC ACC TGA CCC TGG TAT AG & & & R: TGG CAT TCA CGC AGC ATG TGT TG & \\
\hline USP5 & F: GTC CAC AAA GAC GAG TGC GCC T & G1 & USP51 & F: GGA CCC CAG AGA CTA GGA AAC G & G \\
\hline & R: AGG CTG AGT CGG CCG ACA GTA & & & R: CAT AAT CCT TAC ACA TGA AGC A & \\
\hline USP6 & F: CGT TGG AAT CAA CAG CAG CAT TGA & G10 & SP52 & F: TCT GGC AAG GTT TCC CTG AGA GA & $G$ \\
\hline & R: CCA TCC ACT TGC TCG TTC GTG TCA & & & R: GGT TGC CAT GCA CAT CAA AGT CT & \\
\hline USP7 & F: CTC TCA GAC CAT GGG ATT TCC AC & G9 & SP53 & F: GAC ATT TCC AGA GAA TGT GCT CTG & G3 \\
\hline & R: ATT GGT GTG TAG ATA TGC CCA CAG & & & R: GAT CCA GAT TGG AAA TGT GAA AGG & \\
\hline USP8 & F: GAC GCC ACC TGC ATC TAT AGA AG & G1 & USP54 & F: CGT GGT AGT GTA CAA GGG ATG TTT & G2 \\
\hline & R: GGA AAG TAA AAC TGT CCT GCG CAA & & & R: CTC CCA TGC ACT TGT GAG TTG TAA & \\
\hline USP9X & F: AGC TTC AAG GGT TCC AGG ACA AG & G1 & USPL1 & F: TCC CAA GTG ACA GAT AAA GAA GCT G & G12 \\
\hline & R: GAA GAC TAT CTC GCA ACA CTA TGG & & & R: ACC CAC AGA ACA CGA TGT TAA AGA & \\
\hline USpgr & F: GAG GCT GTG AGT GGC TGG AAG T & G9 & VCPIP1 & F: GCT CGC TAT GGA ATG GAC AAA C & G6 \\
\hline & R: CGG ACG TGT ACC ATT GTAAGA TAT G & & & R: ACA TGC TCT GGT TCT ATG AGG & \\
\hline USP10 & F: CCT CCA CAG CCC GCA GTA TAT TT & G3 & YOD1 & F: ACT TGC CCA TCC AAT CTG GTG A & G7 \\
\hline & R: GAG ATA GGA TCA TCG CCA CCA TCT & & & R: ACG TAA CTA GAA GCA CCA CGT T & \\
\hline USP11 & F: TGG TGG AAG GCG AGG ATT ATG TG & G2 & ZRANB1 & F: CTA GTG CAA GAC CAA GGG TG & 66 \\
\hline & R: GCT GGG CCA AGT GCC ATC TTT C & & & R: ACA CAT CTT TTA GCC TTG GCC C & \\
\hline
\end{tabular}

\subsection{Western Blot Analysis}

A2780 and OVCAR5 cells treated with DEHP were lysed using a lysis buffer (50 mM Tris- $\mathrm{HCl}$ (pH 7.5), $300 \mathrm{mM} \mathrm{NaCl}, 1 \mathrm{mM}$ EDTA, 10\% Glycerol, 1\% Triton X-100). After resuspension of cells, samples were incubated for $20 \mathrm{~min}$ on ice and centrifuged at 13,000 rpm for $15 \mathrm{~min}$. Then, cell lysates were mixed with $2 X$ SDS loading buffer, boiled, and loaded into the SDS-PAGE gels. Separated proteins were transferred to polyvinylidene fluoride (PVDF) membranes (IPVH00010, Millipore, 
Billerica, MA, USA), which were incubated overnight with primary antibodies at $4{ }^{\circ} \mathrm{C}$ and then with secondary antibodies for $1 \mathrm{~h}$ at room temperature. Blots were visualized using the ECL reagent solution (LF-QC0101, Young In Frontier, Seoul, Korea).

Table 3. RT-PCR and qRT-PCR primer set.

\begin{tabular}{ll}
\hline DUB Gene & Primer Sequence \\
\hline \multirow{2}{*}{ ATXN3L } & F: 5'-TCA GAA GAA AGT GAT GAG TCT GG-3' \\
& R: 5'-CTC TCA ATT GCT CTC GAA CTT G-3' \\
USP12 & F: 5'-GAA CTC TGA GTC TGG TTA CAT CCT-3' \\
& R: 5'-GAG GAG CTG GTA TCT CTG ATT TCA-3' \\
USP49 & F: 5'-CCC TGA ACG CTA TCA CTG CA-3' \\
& R: 5'-TTG GCC AGC ATC TCA GTG AG-3' \\
COPS5 & F: 5'-GCA GTG GTG ATT GAT CCA ACA A-3' \\
& R: 5'-AGA CCT GAC CAG TGG TAT AGT C-3' \\
USP34 & F: 5'-CAG CCA TAG TGC TGA AGT TCA AGT-3' \\
& R: 5'-GAC TGA CAT CAC CAG ATT GTG CT-3' \\
GAPDH & F: 5'-CCC TGA ACG CTA TCA CTG CA-3' \\
& R: 5'-CCA TCA CGC CAC AGT TTC-3' \\
\hline
\end{tabular}

\subsection{Antibodies}

Rabbit anti-USP49 polyclonal antibody (18066-1-AP) was purchased from Proteintech (Proteintech Group, Chicago, IL, USA) and mouse anti- $\beta$-actin monoclonal antibody (sc-47778) was purchased from Santa Cruz (Santa Cruz Biotechnology, CA, USA).

\subsection{Statistical Analysis}

Each experiment was performed at least three times. Densitometric analysis was performed for bands from all RT-PCR and Western blot results using a computer program Image J software (v1.4.3.67, National Institutes of Health, Bethesda, MD, USA) and the $t$-test using GraphPad Prism version 5 (GraphPad Software, La Jolla, CA, USA). ANOVA was performed by two-way analysis of variance. $p$-values are presented as ${ }^{*} p<0.05,{ }^{* *} p<0.01$, or ${ }^{* * *} p<0.001$ as indicated.

Supplementary Materials: Supplementary materials can be found at http://www.mdpi.com/1422-0067/21/5/1755/ s1. Figure S1. Raw data of repeated multiplex RT-PCR used in this study with A2780 cells, Figure S2. Raw data of repeated multiplex RT-PCR used in this study with OVCAR5 cells, Figure S3. Raw data of repeated RT-PCR used in this study with ovarian cells, Figure S4. Raw data of repeated Western blot used in this study with ovarian cells, Table S1. qRT-PCR data used in this study.

Author Contributions: D.-H.L. designed research, performed the experiments, and wrote the manuscript. J.-H.P. and J.C. helped with performed the experiments and analyzed the data. K.-J.L. and B.-S.Y. helped interpretation of the study. K.-H.B. drafted and critically edited the manuscript. All authors read and provided critical feedback and approved the final version of this manuscript.

Funding: This research was supported by Basic Science Research Program through the National Research Foundation of Korea (NRF) funded by the Ministry of Education (No. NRF-2019R1A6A1A03032888).

Acknowledgments: We would like to thank the members of Baek's laboratory for their critical comments on the manuscript.

Conflicts of Interest: The authors declare no conflict of interest. The funders had no role in the design of the study; in the collection, analyses, or interpretation of data; in the writing of the manuscript, or in the decision to publish the results.

\section{References}

1. Kwon, S.K.; Saindane, M.; Baek, K.H. p53 stability is regulated by diverse deubiquitinating enzymes. Biochim. Biophys Acta Rev. Cancer 2017, 1868, 404-411. [CrossRef] [PubMed]

2. Pickart, C.M. Mechanisms underlying ubiquitination. Annu. Rev. Biochem. 2001, 70, 503-533. [CrossRef] [PubMed] 
3. Woelk, T.; Sigismund, S.; Penengo, L.; Polo, S. The ubiquitination code: A signalling problem. Cell Div. 2007, 2, 11. [CrossRef]

4. Todi, S.V.; Paulson, H.L. Balancing act: Deubiquitinating enzymes in the nervous system. Trends Neurosci. 2011, 34, 370-382. [CrossRef] [PubMed]

5. Abdul Rehman, S.A.; Kristariyanto, Y.A.; Choi, S.Y.; Nkosi, P.J.; Weidlich, S.; Labib, K.; Hofmann, K.; Kulathu, Y. MINDY-1 Is a Member of an Evolutionarily Conserved and Structurally Distinct New Family of Deubiquitinating Enzymes. Mol. Cell 2016, 63, 146-155. [CrossRef] [PubMed]

6. Beck-Peccoz, P.; Persani, L. Premature ovarian failure. Orphanet J. Rare. Dis. 2006, 1, 9. [CrossRef]

7. Jankowska, K. Premature ovarian failure. Prz Menopauzalny 2017, 16, 51-56. [CrossRef]

8. Ayesha, V.J.; Goswami, D. Premature Ovarian Failure: An Association with Autoimmune Diseases. J. Clin. Diagn. Res. 2016, 10, QC10-QC12. [CrossRef]

9. Vabre, P.; Gatimel, N.; Moreau, J.; Gayrard, V.; Picard-Hagen, N.; Parinaud, J.; Leandri, R.D. Environmental pollutants, a possible etiology for premature ovarian insufficiency: A narrative review of animal and human data. Environ. Health 2017, 16, 37. [CrossRef]

10. Tran, D.N.; Jung, E.M.; Yoo, Y.M.; Ahn, C.; Kang, H.Y.; Choi, K.C.; Hyun, S.H.; Dang, V.H.; Pham, T.N.; Jeung, E.B. Depletion of follicles accelerated by combined exposure to phthalates and 4-vinylcyclohexene diepoxide, leading to premature ovarian failure in rats. Reprod. Toxicol. 2018, 80, 60-67. [CrossRef]

11. Yin, J.; Liu, R.; Jian, Z.; Yang, D.; Pu, Y.; Yin, L.; Wang, D. Di (2-ethylhexyl) phthalate-induced reproductive toxicity involved in dna damage-dependent oocyte apoptosis and oxidative stress in Caenorhabditis elegans. Ecotoxicol. Environ. Saf. 2018, 163, 298-306. [CrossRef] [PubMed]

12. Liu, J.C.; Lai, F.N.; Li, L.; Sun, X.F.; Cheng, S.F.; Ge, W.; Wang, Y.F.; Li, L.; Zhang, X.F.; De Felici, M.; et al. Di (2-ethylhexyl) phthalate exposure impairs meiotic progression and DNA damage repair in fetal mouse oocytes in vitro. Cell Death Dis. 2017, 8, e2966. [CrossRef]

13. Absalan, F.; Saremy, S.; Mansori, E.; Taheri Moghadam, M.; Eftekhari Moghadam, A.R.; Ghanavati, R. Effects of Mono-(2-Ethylhexyl) Phthalate and Di-(2-Ethylhexyl) Phthalate Administrations on Oocyte Meiotic Maturation, Apoptosis and Gene Quantification in Mouse Model. Cell J. 2017, 18, 503-513. [PubMed]

14. Hannon, P.R.; Peretz, J.; Flaws, J.A. Daily exposure to Di(2-ethylhexyl) phthalate alters estrous cyclicity and accelerates primordial follicle recruitment potentially via dysregulation of the phosphatidylinositol 3-kinase signaling pathway in adult mice. Biol. Reprod. 2014, 90, 136. [CrossRef] [PubMed]

15. Kim, S.Y.; Kwon, S.K.; Lee, S.Y.; Baek, K.H. Ubiquitin-specific peptidase 5 and ovarian tumor deubiquitinase 6A are differentially expressed in p53+/+ and p53-/- HCT116 cells. Int. J. Oncol. 2018. [CrossRef]

16. Hannon, P.R.; Brannick, K.E.; Wang, W.; Gupta, R.K.; Flaws, J.A. Di(2-ethylhexyl) phthalate inhibits antral follicle growth, induces atresia, and inhibits steroid hormone production in cultured mouse antral follicles. Toxicol. Appl. Pharmacol. 2015, 284, 42-53. [CrossRef] [PubMed]

17. Tzvetkov, N.; Breuer, P. Josephin domain-containing proteins from a variety of species are active de-ubiquitination enzymes. Biol. Chem. 2007, 388, 973-978. [CrossRef]

18. Weeks, S.D.; Grasty, K.C.; Hernandez-Cuebas, L.; Loll, P.J. Crystal structure of a Josephin-ubiquitin complex: Evolutionary restraints on ataxin-3 deubiquitinating activity. J. Biol. Chem. 2011, 286, 4555-4565. [CrossRef]

19. Ge, F.; Chen, W.; Qin, J.; Zhou, Z.; Liu, R.; Liu, L.; Tan, J.; Zou, T.; Li, H.; Ren, G.; et al. Ataxin-3 like (ATXN3L), a member of the Josephin family of deubiquitinating enzymes, promotes breast cancer proliferation by deubiquitinating Kruppel-like factor 5 (KLF5). Oncotarget 2015, 6, 21369-21378. [CrossRef]

20. Cohn, M.A.; Kee, Y.; Haas, W.; Gygi, S.P.; D'Andrea, A.D. UAF1 is a subunit of multiple deubiquitinating enzyme complexes. J. Biol. Chem. 2009, 284, 5343-5351. [CrossRef]

21. Kee, Y.; Yang, K.; Cohn, M.A.; Haas, W.; Gygi, S.P.; D'Andrea, A.D. WDR20 regulates activity of the USP12 x UAF1 deubiquitinating enzyme complex. J. Biol. Chem. 2010, 285, 11252-11257. [CrossRef] [PubMed]

22. McClurg, U.L.; Harle, V.J.; Nabbi, A.; Batalha-Pereira, A.; Walker, S.; Coffey, K.; Gaughan, L.; McCracken, S.R.; Robson, C.N. Ubiquitin-specific protease 12 interacting partners Uaf-1 and WDR20 are potential therapeutic targets in prostate cancer. Oncotarget 2015, 6, 37724-37736. [CrossRef] [PubMed]

23. Joo, H.Y.; Jones, A.; Yang, C.; Zhai, L.; Smith, A.D.t.; Zhang, Z.; Chandrasekharan, M.B.; Sun, Z.W.; Renfrow, M.B.; Wang, Y.; et al. Regulation of histone H2A and H2B deubiquitination and Xenopus development by USP12 and USP46. J. Biol. Chem. 2011, 286, 7190-7201. [CrossRef] [PubMed] 
24. Burska, U.L.; Harle, V.J.; Coffey, K.; Darby, S.; Ramsey, H.; O’Neill, D.; Logan, I.R.; Gaughan, L.; Robson, C.N. Deubiquitinating enzyme Usp12 is a novel co-activator of the androgen receptor. J. Biol. Chem. 2013, 288, 32641-32650. [CrossRef]

25. McClurg, U.L.; Chit, N.; Azizyan, M.; Edwards, J.; Nabbi, A.; Riabowol, K.T.; Nakjang, S.; McCracken, S.R.; Robson, C.N. Molecular mechanism of the TP53-MDM2-AR-AKT signalling network regulation by USP12. Oncogene 2018, 37, 4679-4691. [CrossRef]

26. McClurg, U.L.; Azizyan, M.; Dransfield, D.T.; Namdev, N.; Chit, N.; Nakjang, S.; Robson, C.N. The novel anti-androgen candidate galeterone targets deubiquitinating enzymes, USP12 and USP46, to control prostate cancer growth and survival. Oncotarget 2018, 9, 24992-25007. [CrossRef]

27. Tang, L.J.; Li, Y.; Liu, Y.L.; Wang, J.M.; Liu, D.W.; Tian, Q.B. USP12 regulates cell cycle progression by involving c-Myc, cyclin D2 and BMI-1. Gene 2016, 578, 92-99. [CrossRef]

28. Zhang, Z.; Jones, A.; Joo, H.Y.; Zhou, D.; Cao, Y.; Chen, S.; Erdjument-Bromage, H.; Renfrow, M.; He, H.; Tempst, P.; et al. USP49 deubiquitinates histone $\mathrm{H} 2 \mathrm{~B}$ and regulates cotranscriptional pre-mRNA splicing. Genes Dev. 2013, 27, 1581-1595. [CrossRef]

29. Luo, K.; Li, Y.; Yin, Y.; Li, L.; Wu, C.; Chen, Y.; Nowsheen, S.; Hu, Q.; Zhang, L.; Lou, Z.; et al. USP49 negatively regulates tumorigenesis and chemoresistance through FKBP51-AKT signaling. EMBO J. 2017, 36, 1434-1446. [CrossRef]

30. Tu, R.; Kang, W.; Yang, X.; Zhang, Q.; Xie, X.; Liu, W.; Zhang, J.; Zhang, X.D.; Wang, H.; Du, R.L. USP49 participates in the DNA damage response by forming a positive feedback loop with p53. Cell Death Dis. 2018, 9, 553. [CrossRef]

31. Kim, E.; Yoon, S.J.; Kim, E.Y.; Kim, Y.; Lee, H.S.; Kim, K.H.; Lee, K.A. Function of COP9 signalosome in regulation of mouse oocytes meiosis by regulating MPF activity and securing degradation. PLOS ONE 2011, 6, e25870. [CrossRef] [PubMed]

32. Robker, R.L.; Akison, L.K.; Russell, D.L. Control of oocyte release by progesterone receptor-regulated gene expression. Nucl. Recept. Signal. 2009, 7, e012. [CrossRef] [PubMed]

33. Khan, D.R.; Landry, D.A.; Fournier, E.; Vigneault, C.; Blondin, P.; Sirard, M.A. Transcriptome meta-analysis of three follicular compartments and its correlation with ovarian follicle maturity and oocyte developmental competence in cows. Physiol. Genomics 2016, 48, 633-643. [CrossRef] [PubMed]

34. Zhang, H.; Zhong, A.; Sun, J.; Chen, M.; Xie, S.; Zheng, H.; Wang, Y.; Yu, Y.; Guo, L.; Lu, R. COPS5 inhibition arrests the proliferation and growth of serous ovarian cancer cells via the elevation of p27 level. Biochem. Biophys Res. Commun. 2017, 493, 85-93. [CrossRef] [PubMed]

35. Lui, T.T.; Lacroix, C.; Ahmed, S.M.; Goldenberg, S.J.; Leach, C.A.; Daulat, A.M.; Angers, S. The ubiquitin-specific protease USP34 regulates axin stability and Wnt/beta-catenin signaling. Mol. Cell Biol. 2011, 31, 2053-2065. [CrossRef] [PubMed]

36. Sy, S.M.; Jiang, J.; O, W.S.; Deng, Y.; Huen, M.S. The ubiquitin specific protease USP34 promotes ubiquitin signaling at DNA double-strand breaks. Nucleic Acids Res. 2013, 41, 8572-8580. [CrossRef] [PubMed]

37. Poalas, K.; Hatchi, E.M.; Cordeiro, N.; Dubois, S.M.; Leclair, H.M.; Leveau, C.; Alexia, C.; Gavard, J.; Vazquez, A.; Bidere, N. Negative regulation of NF-kappaB signaling in T lymphocytes by the ubiquitin-specific protease USP34. Cell Commun. Signal. 2013, 11, 25. [CrossRef]

38. Zhao, S.; Tian, Y.; Zhang, W.; Xing, X.; Li, T.; Liu, H.; Huang, T.; Ning, Y.; Zhao, H.; Chen, Z.J. An association study between USP34 and polycystic ovary syndrome. J. Ovarian. Res. 2015, 8, 30. [CrossRef]

(C) 2020 by the authors. Licensee MDPI, Basel, Switzerland. This article is an open access article distributed under the terms and conditions of the Creative Commons Attribution (CC BY) license (http://creativecommons.org/licenses/by/4.0/). 